\title{
Suppurative Cranial Complications of Sinusitis, Management with Limited Resources: A Report of Two Cases with a Review of the Literature
}

\author{
Sharma B. Sudhir \\ ENT Consultant, G.P.H.C., Georgetown, Guyana
}

*Corresponding author: Dr. Sharma B. Sudhir, ENT Consultant, G.P.H.C., A-168, Eping's avenue, Belair Park, Georgetown, Guyana, Tel: 592-6782013/ Fax: gphchosp@hotmail.com; E-mail: sbs1950@rediffmail.com

\begin{abstract}
Unusual clinical presentations of intra cranial suppurative complication of sinusitis make it difficult to be to be diagnosed and make it a challenging task. Even in present time this pathology is known to produce significant morbidity and mortality. A short review of the literature on ICS has been done with our experience of two cases who had varying clinical presentations and inspite of their management with limited available resources, both the cases recovered fully with limited morbidity. The first case, a 12 years old boy had no clinical evidence of sinusitis but had high fever, signs of increased intra cranial pressure, orbital cellulites and abscesses on left upper eye lid and on same side of forehead. The CT scan revealed Fronto- Maxillary sinusitis, periorbital cellulites, lid and forehead abscesses along with oedema in brain for which an external Fronto-Ethmoido-Maxillary antrostomy [Lynch-Howarth operation] was done along with drainage of extra cranial abscesses in the eyelid and forehead.

The second case, a 21 years old female, known to have nasal allergies had a high fever, right eye congested and proptosed and had signs of increased ICP. The CT and MRI revealed that she had a subdural empyma, Frontal sinusitis and a periorbital Cellulites. The subdural empyma was drained by a neuro- surgeon and the sinus abscesses were drained [Lynch Howarth operation] by an Otolaryngologist, at the same time. Both the patients recovered in 4 to 6 week. In conclusion, the diagnosis of ICS requires a high index of suspicion and early radiographic imaging [CT/MRI] of the head and paranasal sinuses. An aggressive medical therapy is indicated and it may require drainage of the sinus abscess and the intra cranial abscess, at the same time.
\end{abstract}

Received Date: August 10, 2016 Accepted Date: July 04, 2017 Published Date: July 07, 2017

Citation: Sharma, B.S. Suppurative Cranial Complications of Sinusitis, Management with Limited Resources: A Report of Two Cases with a Review of the Literature. (2017) Int J Neuro Brain Dis 4(1): $1-5$.

DOI: $10.15436 / 2377-1348.17 .1045$

Synopsis: The objective is to gain insight into patterns of presentation, imaging, microbiological aspects and management of a suppurative ICS, a pathology with high rate of morbidity and mortality. It becomes more challenging if it has to be managed with limited resources including a lack of FESS technique of draining the sinus abscesses.

Keywords: Sinusitis; Sinostomy; ICS (intra cranial complication of sinusitis); Subdural empyma; PNS (paranasal Sinus); E.N.T (ear, nose and throat); ICP (intra cranial pressure); Epidural abscess; FESS [Functional Endoscopic Sinus Surgery]

\section{Introduction}

Intracranial complications of paranasal sinusitis have become rare due to widespread and early use of antibiotics. Potentially life-threatening intracranial complications of sinusitis include subdural empyma, epidural and intracerebral abscess, meningitis and sinus thrombosis. Patients with intracranial complication of sinusitis can present without neurological signs, which may delay diagnosis and correct treatment ${ }^{[1]}$. The infection from the sinuses, producing "intra cranial complication of sinusitis" [ICS], is mainly by septic thrombi through the valve less diploic veins of the skull base that penetrate the dura ${ }^{[2]}$ or sometimes via direct extension by osteomyelitis of the bony sinus walls or through existing bony defects (congenital or post traumatic). The frontal skull is vulnerable 
because of its high vascularity, rich network of diploic veins and frequently associated anterior ethmoid sinusitis. The suppurative intracranial infections like meningitis, epidural abscess, subdural empyma, thrombosis of cavernous sinus and other dural sinuses and encephalitis are uncommon but serious sequelae of paranasal sinusitis and a high index of suspicion is necessary to identify these serious complications. We present a patient with subdural empyma in whom the diagnosis was delayed and it deteriorated rapidly producing a true neurosurgical emergency, similar to a finding in a series ${ }^{[3]}$ stating that a subdural empyma requires a prompt diagnosis and management. Location of an intracranial infection strongly influences the clinical presentation and the disease course. Extra cranial complications, especially orbital infections commonly coexist with ICS. These concurrent orbital and forehead complications often have a predilection for epidural abscesses and their presence increase the likelihood of earlier diagnosis of ICS.

Most important investigation is a CT scan or a MRI. An ICS can be prevented by an early diagnosis and treatment of sinusitis by a medical treatment and, if required, by a surgical intervention like the drainage of the sinuses by antrum lavage, a functional endoscopic sinus surgery (FESS) or by an external approach antrostomy. Once diagnosed, the management for ICS requires an aggressive treatment offered by a physician [including culture directed intravenous antibiotics which penetrate cerebrospinal fluid] and the abscesses [of sinus and intra cranial collection] need surgical drainage by an otolaryngologist along with a neurosurgeon, at the same time.

\section{Methods}

To review the literature on ICS [patterns of presentation, imaging, microbiology, FESS therapy, disease course and it is sequelae] the references were taken from different series of studies to compare with our experience of two cases.

\section{Case Reports}

\section{First Case}

A 12 years old boy presented with cough and cold, left sided headache with same side swollen eye, high fever, vomiting and an abnormal behavior for two days. The past history and clinical examination revealed nothing significant for E.N.T. pathology hence a provisional diagnosis of left orbital cellulites with meningitis was made and a treatment started by a physician but the condition deteriorated and also an abscess developed on his forehead [figure; 2a]. A Lumber puncture was done where the CSF was straw colored, cloudy and had normal pressure with glucose120mg, proteins -56 mg, WBC 1536 /c.m.m. [predominantly neutrophils] and RBC 186 /c.m.m. The Gram stain of C.S.F. revealed bacteria and the culture showed coagulates negative Staphylococci species [sensitivity not done]. These findings suggested a bacterial meningitis and a radiology investigation was required hence advised a CT scan and MRI but patient could not afford it in private set up so an X-ray of P.N.S. was advised which revealed a fluid level in the right Maxillary sinus and the mucopus was drained by an antrum lavage. Still his condition worsened, developed generalized seizures and somehow a CT scan [figure; $2 b, c$.] was managed to be done which showed an opacity in left maxillary and ethmoidal sinuses, left periorbit- al and frontal sub-scalpular abscesses and brain oedema. In the management an external Fronto- Maxillary-Ethmoidal antrostomy [Lynch Howarth's operation] was done [in lack of FESS facility] along with draining of periorbital and frontal sub-scalpular abscesses [figure; 3a, b.]. The drained pus, on culture and sensitivity showed Gram positive coccid- sensitive to (already receiving) Amoxicillin + Clauvanic acid and the same parenteral antibiotics were continued. The patient recovered in next three weeks [figure; $3 \mathrm{c}$.$] .$

Figures 1-3
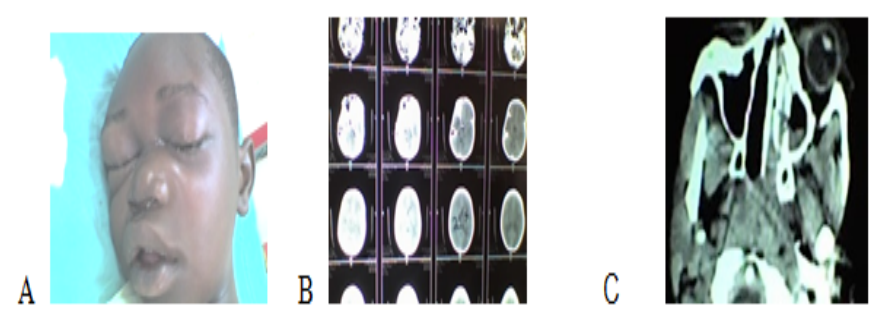

Figure 1: A - Periorbital cellulitis with sinusitis; B - CT scan of PNS; C - CT scan of brain.

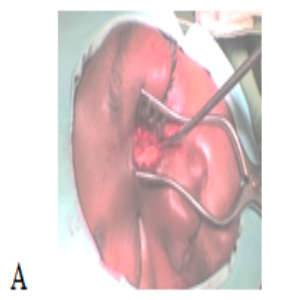

B

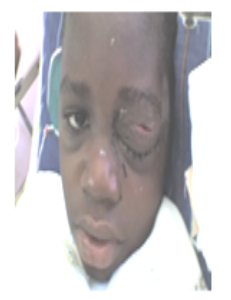

C

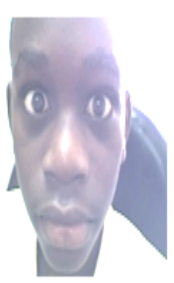

Figure 2: A-External Fronto maxillary Sinostomy; B-Post op. picture with I\&D of lid abscess; C- Full recovery in 3 weeks.

A
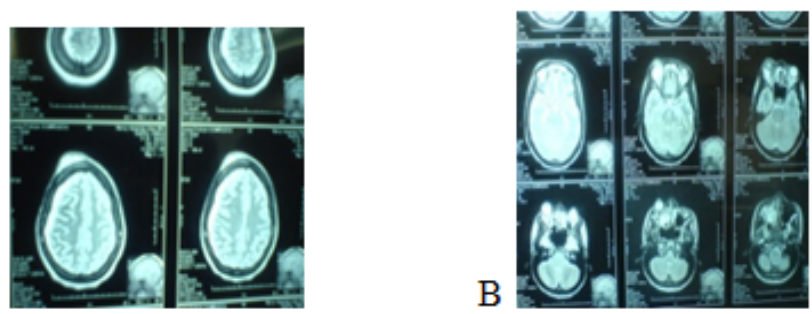

Figure 3: A, B- MRI revealed empymas in Rt. Maxillary sinus, Retro bulbar and subdural space along with the Cavernous Sinus thrombosis.

\section{Second case}

A 21 yrs. old female had high fever, nausea, headache, altered mental status, swelling over right eyelids and blood mixed mucopurulent nasal discharges for three days. In her past history, she had of frequent attacks of nasal allergy and sinusitis. She had tenderness over right Frontal and Maxillary sinuses. On $4^{\text {th }}$ day of admission the patient started showing signs and symptoms of increased ICP by having focal seizures, short spells of unconsciousness and a temporary monoplegia of right upper arm. She had constant high fever and high leukocyte count and soon she developed a scalp abscess on right fronto-parietal region. A CT scan and MRI showed right Maxillary and Ethmoidal sinusitis, right retro bulbar orbital and subdural abscesses along with cavernous sinus thrombosis [figure; 3a,b.]. The subdural empyma was drained through bur holes [figure; 5 b.] by a neurosurgeon and during the same anesthesia, the Maxillary, Ethmoid and the 
Frontal sinuses were drained [figure; 5a.] through an external route [Lynch Howarth's operation] by an otolaryngologist. The Gram's stain [of the pus from sinuses] revealed Gram-positive bacteria but no growth was found on culture. Post operatively bilateral Lateral rectus palsy [figure; 6a.] was noticed but it fully recovered in next 6 weeks [figure: 6b]. Results- Both the cases recovered fully in spite of non FESS [ external sinostomy] management, the child in 2 weeks and the adult who had a morbidity of bilateral Lateral rectus palsy, recovered in 6 weeks. Both the patients were discharged with prescription of broad spectrum antibiotics for 4 weeks and anti-epileptics [Phenytoin], six months for the child and one year for the adult case. Figures- 4,5

A



\section{B}

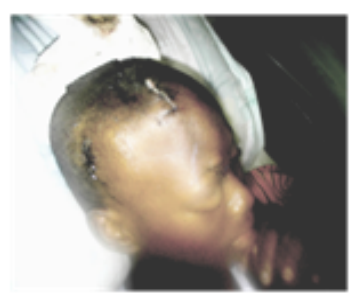

Figure 4: A - Maxillary and Frontal sinus External Sinostomy; B - Subdural empyma, drained through bur holes.

A

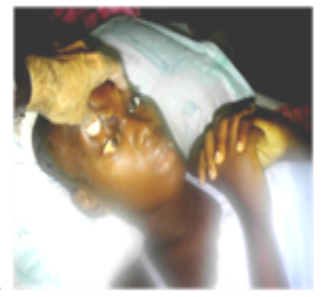

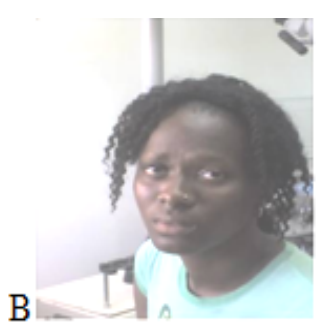

Figure 5: A- Bilateral lateral rectus palsy; B-Patient fully recovered in six weeks.

\section{Discussion}

This serious pathology can be diagnosed early and managed efficiently with help of advanced radiology [CT scan and MRI] and surgical techniques [FESS and neurosurgery] and in absence of these facilities it becomes a challenging task. Guyana, a former British colony with a population of 751,000, is one of the poorest countries of the Americas and has one of the lowest health status indicators of its region. There are only a handful of Otolaryngology specialists. Georgetown Public Hospital Corporation (GPHC) serves as the national tertiary care teaching hospital where the majorities of complicated otolaryngology cases are seen and are faced daily with challenges ${ }^{[4]}$. There is a lack of modern surgical equipments and skill [for FESS], consumables in pathology [microbiology and histopathology] and an affordable advanced radiology [CT/MR]. It is within this context that we describe the diagnosis and management of two cases who had a rare and serious complication of sinusitis.

J.A. Griller, et $\mathrm{al}^{[5]}$ reviewed different series of studies on suppurative ICS and found out that most of the patients [including ours] had no history of prior sinus surgery and usually the symptoms are nonspecific like fever, headache, facial swelling, the ocular findings like proptosis and periorbital cellulites and the common neurologic symptom was mental status change [disorientation]. Similarly T.K. Nicoli, et $\mathrm{a}^{[6]}$ in their study, had the patients who presented with signs of raised intracranial pressure rather than signs of sinusitis and the most common presenting complaint was headache $(100 \%)$ followed by fever $(83 \%)$, nasal congestion $(50 \%)$, vomiting $(50 \%)$ and forehead lump (34\%). All patients were managed surgically [neurosurgical intervention and evacuation of the abscess, as early as possible] and most $(83 \%)$ patients recovered to premorbid state without neurological sequelae. In another study ${ }^{[7]}$, neurological signs were the most frequent symptoms but contrary to our cases the rhinological signs were essentially purulent rhinorrhea and nasal obstruction. The duration of symptoms [pain and swelling on face] was shorter [ 3 days] contrary to 12 days, in series ${ }^{[5]}$. In the adult case the ICS was secondary to chronic sinusitis as found in the series ${ }^{[8]}$ and in the child case it was secondary to acute sinusitis as seen in a pediatric series ${ }^{[9]}$. The hospital stay was 28 days for the adult and 14 days in the child case similar to stay of 15 - 30 days seen in few series ${ }^{[5,9]}$. Clinical presentation and the disease course depend on the site of intracranial infection ${ }^{[10]}$. The adult case had a subdural empyma, a common intra cranial complication of sinusitis as mentioned in the series ${ }^{[11,12,13]}$ and in the child case it was the epidural abscess, commonly seen as in the series ${ }^{[8,14,15]}$. In a study ${ }^{[7]}$ of 23 patients of ICS, as per CT scan there were subdural empymas (11 cases), extradural empymas ( 7 cases) and brain abscesses ( 5 cases). Associated cerebral thrombophlebitis was noted in 4 cases. Our presented child case had extra cranial complication [Frontal sub scalpular abscess and orbital cellulites], commonly associated with epidural abscesses ${ }^{[13,16]}$. Epidural abscesses progress slowly than subdural empymas ${ }^{[10,17]}$ and are diagnosed early [by showing extra cranial complications] hence have better outcomes in management, was found in the series ${ }^{[11,14,16]}$. By contrast, the subdural empyma spreads rapidly and freely within a preformed space, typically resulting in a more culminant acute presentation with early neurologic deficits [as in our adult case]. "Silent" intracranial involvement is common, especially in children ${ }^{[13,14,16]}$ and our child case also showed no neurological deficit. Though an antrum lavage was done in the affected child but still he had complications, justifying that a high index of suspicion for concurrent ICS must be maintained when sinusitis fails to respond to therapy. CT scan and MRI are more accurate for localizing the subdural empyma ${ }^{[18]}$ and a MRI is superior to a CT scan in localizing the intracranial collections, as in our adult case. Functional Endoscopic Sinus Surgery [FESS] is indicated in nearly all the patients [even who do not require neurosurgery because of small or thin collections] as it gives favorable outcomes and low morbidity. In our cases, only external exploration for sinuses was done, as we have no FESS facility. In another series ${ }^{[1]}$ of 23 patients with ICS, Twenty two patients $(96 \%)$ had radiologic evidence of frontal sinusitis with prefrontal or frontal lobe ICS at presentation suggesting that Intracranial complications of sinusitis usually result from direct spread of acute frontal sinusitis Endoscopic sinus surgery and intravenous antibiotics as initial treatment was successful in avoiding craniotomy in only 1 of 6 patients again suggesting that ESS did not appear to alter the need for neurosurgical intervention, which was ultimately necessary in most patients hence the role of ESS in the initial treatment of ICS is not clear. In this series of 23 patients, 18 underwent neurosurgical procedures, 9 for emergent procedures for abscesses more than $1 \mathrm{~cm}$ and 9 underwent delayed procedures for persistent disease despite ICS less than $1 \mathrm{~cm}$ at presentation. 
On culture of pus from our cases, Gram's positive bacteria were seen as in series ${ }^{[4]}$ where gram positive multiple organisms grew in $54 \%$ of patients [predominated Streptococcus milleri group and Staphylococci A coagulase negative species].The intracranial complications of sinusitis are serious and source of important morbidity and mortality. Management should be rapid and adequate, combining effective antibiotic therapy and eventually neurosurgical treatment ${ }^{[1,3,7]}$. Table $1-4$

Table 1: Review for symptoms, signs and its duration.

\begin{tabular}{|c|c|c|}
\hline $\begin{array}{l}\text { Clinical presentation and the disease course } \\
\text { (depend upon the site of lesion) }{ }^{[10]} \text {. }\end{array}$ & $\begin{array}{l}\text { The presented cases, to start with, had no specific } \\
\text { symptoms like - high fever, headache, and nau- } \\
\text { sea though later both had signs of raised intracra- } \\
\text { nial pressure, the common neurologic symptom } \\
\text { being a change of mental status [disorientation]. } \\
\text { In past history- the child case[with meningitis } \\
\text { only] had no symptoms and signs of sinusitis but } \\
\text { the adult case [advanced stage of ICS] had a his- } \\
\text { tory of frequent rhinosinusitis with blood mixed } \\
\text { mucopurulent nasal discharges and in signs, had } \\
\text { tender sinuses. }\end{array}$ & $\begin{array}{l}\text { Similar non specific presenting symptoms } \\
\text { were found in most series of studies }{ }^{[5,6]} \text { and in } \\
\text { advanced stage of complications neurological } \\
\text { signs and symptoms were the most frequent } \\
\text { along with rhinological presentation like pu- } \\
\text { rulent rhinorrhea and nasal obstruction }{ }^{[7]} \text {. }\end{array}$ \\
\hline The duration & $\begin{array}{l}\text { The duration of symptoms in our cases was } 3 \\
\text { days [average]. }\end{array}$ & $\begin{array}{l}\text { The duration of symptoms was stated to be } 12 \\
\text { days in average in other studies }{ }^{[5]}\end{array}$ \\
\hline
\end{tabular}

Table 2: Review for prior sinus surgery, extra cranial extensions, neurological deficits and the hospital stay.

\begin{tabular}{|l|l|l|}
\hline Prior history of sinus surgery & Both the cases had no such history & $\begin{array}{l}\text { Similarly no such history was found in a comparative } \\
\text { study of different series by Griller et al }{ }^{[5]}\end{array}$ \\
\hline Extra cranial extension of ICS & $\begin{array}{l}\text { The child case [not in adult case] with intracranial } \\
\text { epidural abscess had extra cranial extension like } \\
\text { frontal sub scalpular abscess and orbital cellulites. }\end{array}$ & $\begin{array}{l}\text { Extra cranial extension is commonly associated with } \\
\text { epidural abscesses }\end{array}$ \\
\hline $\begin{array}{l}\text { Intra cranial infection and neuro- } \\
\text { logical deficit }\end{array}$ & $\begin{array}{l}\text { The child case showed no neurological deficit as } \\
\text { he had a "Silent" intracranial involvement but the } \\
\text { adult case had neurological deficit. }\end{array}$ & $\begin{array}{l}\text { "Silent" intracranial involvement is common, especial- } \\
\text { ly in children }{ }^{[13,14,17]}\end{array}$ \\
\hline Hospital stay of patients with ICS & $\begin{array}{l}\text { The hospital stay was 28 days for the adult and 14 } \\
\text { days in the child case }\end{array}$ & $\begin{array}{l}\text { Similar stay of } 15 \text { - 30 days was noticed in other studies } \\
\text { too }^{[9,14]} \text {. }\end{array}$ \\
\hline
\end{tabular}

Table 3: Review for the site of Lesion, role of radiology and treatment.

\begin{tabular}{|l|l|l|}
\hline Site of Lesion & $\begin{array}{l}\text { The adult case had a subdural empyma and the } \\
\text { child case had an epidural abscess. Both the } \\
\text { cases had Fronto-Ethmoido-Maxillary sinusitis } \\
\text { on the affected side. }\end{array}$ & $\begin{array}{l}\text { Subdural empyma has been reported as a common site in all Intra } \\
\text { cranial suppurations due to sinusitis } \\
\text { seen a common ICS, in series with children } \text { and }^{[14]} \text {. Frontal sinus- } \\
\text { itis was the commonest cause of epidural abscess in adults and chil- } \\
\text { dren }^{[8,15]} .\end{array}$ \\
\hline CT scan and MRI & $\begin{array}{l}\text { CT scans were done for both the cases and a } \\
\text { MRI was also done for the adult case. }\end{array}$ & $\begin{array}{l}\text { Similar were the findings }{ }^{[18]} \text { that CT scan and MRI are more accurate } \\
\text { for localizing the subdural empyma and a MRI is superior to a CT } \\
\text { scan in localizing the intracranial collections, }\end{array}$ \\
\hline $\begin{array}{l}\text { Role of treatment on } \\
\text { progress of ICS }\end{array}$ & $\begin{array}{l}\text { An antrum lavage [in child case] and broad } \\
\text { spectrum antibiotics [in both cases] could not } \\
\text { control ICS. } \\
\text { In both the cases the sinus abscesses were } \\
\text { drained along with that extra cranial [in child] } \\
\text { and intra cranial [in adult] and both recovered } \\
\text { without any neurological sequelae. }\end{array}$ & $\begin{array}{l}\text { Many studies advocate that a high index of suspicion for concur- } \\
\text { rent ICS must be maintained when sinusitis fails to respond to ther- } \\
\text { apy } \\
\text { Similar drainage of the abscesses [intra cranial, by neurosurgeon and } \\
\text { involved sinuses by otolaryngologist] made most patients recovered } \\
\text { to premorbid state without neurological sequelae }\end{array}$ \\
\hline
\end{tabular}

Table 4: Review for the progress of the disease.

\begin{tabular}{|l|l|l|}
\hline Progress of the disease & $\begin{array}{l}\text { In the child case [epidural abscess] the disease } \\
\text { progressed slowly and was diagnosed early by } \\
\text { showing the extra cranial complications. } \\
\text { In the adult case [subdural empyma]- the } \\
\text { spread was rapid and had a more culminant } \\
\text { acute presentation with early neurologic defi- } \\
\text { cits }\end{array}$ & $\begin{array}{l}\text { Epidural abscesses progress slowly than sub- } \\
\text { dural empymas and are diagnosed early }{ }^{[13,16]} \\
\text { hence have better outcomes in manage- } \\
\text { ment }{ }^{[1,14,16]}\end{array}$ \\
$\begin{array}{l}\text {-Subdural empyma spreads rapidly and free- } \\
\text { ly within a preformed space so it has a more } \\
\text { culminant acute presentation with early neu- } \\
\text { rologic deficits }\end{array}$ \\
\hline 10,17$].$
\end{tabular}




\section{Limitations:}

1. The study of presented two cases make it a very small study to compare with other series of study.

2. FESS facilities are not available in our institution.

3. We have limitations to advice for CT scan and MRI as these are not done free of charge in Guyana and many patients cannot afford it.

4. Microbiology, culture and sensitivity studies are sometimes unavailable or delayed [due to shortage of consumables in lab. [With these limitations it becomes a challenge to manage these cases].

\section{Conclusion and Recommendations}

Diagnosis of ICS requires a high index of suspicion and early radiology of the head and PNS [CT scan and MRI] is crucial to diagnosis. Treatment has to be aggressive like medical therapy combined with surgical interventions by an otolaryngologist and neurosurgeon so as to improve the outcomes and to reduce the mortality and morbidity. A variety of surgical approaches can be used, traditional being intranasal and external nasal approaches. However, transnasal endoscopic approaches [FESS] are most commonly employed due to their superior visualization of disease process and anatomy, reduced operating time, decreased blood loss, and decreased morbidity compared to non-endoscopic approaches ${ }^{[1]}$. Unfortunately FESS instruments and skill, both are not available in Guyana hence an external nasal approach had to be performed as otolaryngologists in low-resource countries have to adapt to available limited resources. Advancements in technology including CT, MRI and endoscopic sinus surgery have allowed better understanding and management of ICS and there is always a need of global collaborations and help from international colleagues for training and providing the skill for advanced surgical techniques to developing poor countries.

Acknowledgement-Thanks to the Director and the management staff of G.P.H.C., Georgetown for giving permission to use records of the reported cases and for its publication. My sincere thanks to the authors who are mentioned in the references.

\section{References}

1. Del Gaudio, J.M., Evans, S.H., Sobol, S.E., et.al. Intracranial Complications of Sinusitis: What Is the Role of Endoscopic Sinus Surgery in the Acute Setting? (2010) Am J Otolaryngol 31(): 25-28.

PubMed |Crossref | Others

2. Bradley, P.J., Manning, K.P., Shaw, M.D. Brain abscess secondary to par nasal sinusitis. (1984) J Laryngol Otol 98(7): 719-725.

PubMed | Crossref| Others

3. Bayonne, E., El Bakkouri, W., Kania, R., et.al. Cranial and Endocranial Complications of Sinonasal Infections. (2007) EMC - Oto-Rhino-Laryngologie 2: 20-445-A-10.

PubMed | Crossref $\mid$ Others
4. Siu, J., Sharma, B.S., Sowerby, L. Unilateral isolated sphenoid sinusitis with contra lateral abducens nerve palsy - A rare complication treated in a low-resource setting. (2015) J Otolaryngol Head Neck Surg 44: 9

PubMed | Crossref $\mid$ Others

5. Griller, J.A., Mooning, D.L., Spartan, A.M., et.al. Intracranial Complications of Sinusitis in Children and Adolescents and Their Outcomes. (2006) Arch Otolaryngol Head Neck Surg 132(9): 969-976. PubMed | Crossref| Others

6. Nicoli, T.K., Oinas, M., Niemelä, M., et.al. Intracranial Supportive Complications of Sinusitis. (2016) Scandinavian J Surg 105(4): 254-262.

PubMed $\mid$ Crossref $\mid$ Others

7. Khaled, K., Madiha, M., Ayoub, B. Y., et.al. Management of Intracranial Complications of Sinusitis. (2015) Open J Clin Diag 5(2): 86-95.

PubMed |Crossref | Others

8. Gallagher, R.M., Gross, C.W., Phillips, C.D. Suppurative intracranial complications of sinusitis. (1998) Laryngoscope 108(11 Pt 1): 16351642.

PubMed |Crossref| Others

9. Giannoni, C., Sulek, M., Friedman, E.M. Intracranial complications of sinusitis: a pediatric series. (1998) Am J Rhinol 12(3): 173-178.

PubMed | Crossref $\mid$ Others

10. Heilpern, K.L., Lorber, B. Focal intracranial infections. (1996) Infect Dis Clin North Am 10(4): 879-898.

PubMed |Crossref | Others

11. Nielsen, H. Cerebral abscess in children. (1983) Neuropediatrics 14(2): 76-80.

PubMed | Crossref | Others

12. Maniglia, A.J., Goodwin, W.J., Arnold, J.E., et.al. Intracranial abscesses secondary to nasal, sinus, and orbital infections in adults and children. (1989) Arch Otolaryngol Head Neck Surg 115(12): 14241442 .

PubMed | Crossref | Others

13. Jones, N.S., Walker, J.L., Basis, S., et.al. The intracranial complications of rhinosinusitis: can they be prevented? (2002) Laryngoscope 112(1): 59-63.

PubMed | Crossref | Others

14. Lerner, D.N., Choi, S.S., Zalzal, G.H., et al. Intracranial complications of sinusitis in childhood. (1995) Ann Otol Rhinol Laryngol 104(4 Pt 1): 288-293.

PubMed | Crossref| Others

15. Altman, K.W., Austin, M.B., Tom, L.W., et.al. Complications of frontal sinusitis in adolescents: case presentations and treatment options. (1997) Int J Pediatr Otorhinolaryngol 41(1): 9-20.

PubMed | Crossref| Others

16. Singh, B., Van Dellen, J., Ramjettan, S., et.al. Sinogenic intracranial complications. (1995) J Laryngol Otol 109(10): 945-950.

PubMed | Crossref| Others

17. Bambakidis, N.C., Cohen, A.R. Intracranial complications of frontal sinusitis in children: Pott's puffy tumor revisited. (2001) Pediatr Neurosurg 35(2): 82-89.

PubMed |Crossref| Others

18. Heran, N.S., Steinbok, P., Cochrane, D.D. Conservative neurosurgical management of intracranial epidural abscesses in children. (2003) Neurosurg 53(4): 893-897.

PubMed |Crossref| Others

19. Osborn, M.K., Steinberg, J.P. Subdural Empyema and Other Suppurative Complications of Paranasal Sinusitis. (2007) The Lancet Infect Dis 7(1): 62-67. http://dx.doi.org/10.1016/S1473-3099(06)70688-0

PubMed | Crossref| Others
Online ISSN: $2377-1348$

Journal Title: International Journal Neurology and Brain Disorders Journal Short Name: Int J Neurol Brain Disord
Ommega Online Publishers

E-mail: neurology@ommegaonline.com

Website: www.ommegaonline.org 